\title{
Helen Salisbury: Oh, those lazy, part time GPs!
}

\author{
Helen Salisbury GP \\ Oxford
}

Last week the Daily Mail ran a story claiming that only a third of GPs were working full time at their surgeries. It went on to say that "some think the traditional family doctor role has become monotonous, while others find the full-time hours exhausting." A sessional GP was quoted, describing the work as "ticking boxes rather than dealing with people" and reporting frustration from patients who were waiting too long for an appointment.

I find myself wondering why the press wishes to paint us as lazy and uninterested, and whether this has any connection with politics. If the crisis in GP accessibility is the fault of slacking GPs, then those in charge of workforce planning and resources are off the hook. And is there just a hint of misogyny, given that many women work and raise families? Or perhaps the problem is that we're overpaid if we can afford to work part time.

Why are we working less than full time? Firstly, let's look at a GP's day. Some salaried doctors do work to contract, doing 8.5 hour days, but they're in the minority. Most employed doctors in general practice work well beyond their contracted hours, as it's impossible to get the job done within them. The timetable usually doesn't reflect the reality: 10 or 15 minute appointments can easily over-run, and each one may generate a referral, a letter, or liaison with district nurses or social services. Many practices at least attempt to protect salaried doctors from excessive workloads, and partners are left to pick up the rest. Many routinely work 12 hours on a clinical day, occasionally 14. If a full time job is 37 hours a week, a lot of GPs reach that after three days.

So, what else are we doing when we're not at the surgery? Some GPs have other responsibilities, such as caring for children or older relatives. Many more are doing paid work, in what are referred to as "portfolio careers." Some teach medical students, creating a workforce for the future. Some practise as GPs with a special interest, bringing their community expertise to specialist clinics and plugging staffing gaps there. Many work evenings and weekends in extended hours services or as GPs at the hospital front door. ${ }^{2} \mathrm{~A}$ few are burdened with trying to do something constructive with the new primary care networks. Should we stop doing all of these things?

I'm heavily invested in the concept of continuity of care and the benefits it brings to doctors and patients. The work is easier and more rewarding if you know your patients, but some doctors are cautious about taking on the responsibility of a personal list and so have less experience of this.

However, whatever your status, current general practice is intense, and doctors risk burning out: facing more demand than you can cope with is stressful. The fact that some protect themselves by choosing not to work in their surgery every day is completely sensible. The choice for many is between "part time" GP work or no GP work at all. GP bashing from the press, and demanding that we become more resilient and work longer in our surgeries, is likely to be counterproductive.

\section{Competing interests: See www.bmj.com/about-bmj/freelance-contributors.} Provenance and peer review: Commissioned; not externally peer reviewed.

Borland S, Leatham X. Only a third of GPs are working full-time in surgeries amid a crisis in patients being able to book appointments, NHS figures reveal. Mail Online 2019 Nov 29. https://www.dailymail.co.uk/health/article-7740355/Only-GPs-working-time-surgeries. html.

Salisbury H. Helen Salisbury: Poaching in practice. BMJ 2019;366:14947. 10.1136/bmj.14947 31387852

Published by the BMJ Publishing Group Limited. For permission to use (where not already granted under a licence) please go to http://group.bmj.com/group/rights-licensing/ permissions 